\title{
SISTEM PENGELOLAAN LUBUK LARANGAN SEBAGAI BENTUK KEARIFAN LOKAL DI SUNGAI BATANG TEBO KABUPATEN BUNGO PROVINSI JAMBI
}

\author{
Merry Handayani*, Djunaidi** dan Rini Hertati** \\ * Alumnus Program Studi Pemanfaatan Sumberdaya Perikanan Fakultas Perikanan \\ ** Dosen Program Studi Pemanfaatan Sumberdaya Perikanan Fakultas Perikanan
}

\begin{abstract}
ABSTRAK
Lubuk Larangan merupakan salah satu bentuk kearifan lokal yang merupakan salah satu warisan budaya yang ada di masyarakat (tradisional) dan secara turun-menurun dilaksanakan oleh Masyarakat yang bersangkutan. Kearifan lokal tersebut umumnya berisi ajaran untuk memelihara dan memanfaatkan sumberdaya alam (hutan, tanah, dan air) secara berkelanjutan.

penelitian ini bertujuan untuk mengetahui sistem pengelolaan lubuk larangan sebagai bentuk kearifan lokal di Perairan Sungai Batang Tebo, Kabupaten Bungo Provinsi Jambi.

Metode penelitian yang di gunakan adalah porposive sampling yaitu penentuan stasiun penelitian sesuai dengan tujuan penelitian, survey dan wawancara langsung kepada Masyarakat yang terlibat di dalam proses Sistem Pengelolaan Lubuk Larangan sebagai bentuk kearifan lokal di Perairan Sungai Batang Tebo Kabupaten Bungo.

Berdasarkan hasil penelitian yang telah dilakukan maka dapat disimpulkan, bahwa sistem pengelolaan lubuk larangan di :

Dusun Tanah Tumbuh Kecamatan Tanah Tumbuh sudah menggunakan sistem pengelolaan yang sesuai dengan kearifan lokal baik dari sistem perencanaan, pengorganisasian, pelaksanaan, dan pengawasan.

Sistem pengelolaan lubuk larangan Dusun Tuo Lubuk Mengkuang dan Dusun Muara Tebo Pandak Kecamatan Limbur Lubuk Mengkuang belum terkelola secara baik hal ini dibuktikan tidak adanya sistem pengawasan terhadap lubuk larangan.
\end{abstract}

Kata Kunci : Sistem Penegelolaan, Lubuk Larangan, kearifan lokal dan konservasi.

\section{PENDAHULUAN}

Lubuk Larangan merupakan salah satu bentuk kearifan lokal yang merupakan salah satu warisan budaya yang ada di Masyarakat (tradisional) dan secara turunmenurun dilaksanakan oleh Masyarakat yang bersangkutan. Kearifan lokal tersebut umumnya berisi ajaran untuk memelihara dan memanfaatkan sumberdaya alam (hutan, tanah, dan air) secara berkelanjutan (Lampe dalam Amin Parwati, 2012).

Sungai Batang Tebo merupakan Sungai yang terdapat di Kabupaten Bungo. panjang Sungai Batang Tebo mencapai kurang lebih $140 \mathrm{~km}$ sedangkan lebar dari Sungai Batang Tebo yaitu 150-300 meter dan dengan kedalaman 8- 12 meter,di sepanjang Sungai Batang Tebo banyak terdapat lubuk larangan sebagai bentuk kearifan lokal bagi Masyarakat setempat. Jumlah Lubuk Larangan di Sepanjang Sungai Batang Tebo Kabupaten Bungo Yaitu : Sebanyak 121 lokasi Lubuk Larangan. yang tersebar hampir di seluruh Kecamatan dalam Kabupaten Bungo. 
SEMAH : Journal Pengelolaan Sumberdaya Perairan VOL. 2 No. 3

Desember 2018

Sedangkan di Sungai Batang Tebo terdapat 39 buah lubuk larangan. (Dinas Peternakan dan Perikanan Kabupaten Bungo, 2016).

Dari seluruh banyak lubuk larangan tersebut dapat di lihat belum ada data atau imformasi tertulis tentang sistem pengelolaan lubuk larangan di sepanjang perairan Batang Tebo. berdasarkan hal di atas, maka perlu di lakukakan penelitian tentang Sistem Pengelolaan lubuk larangan sebagai bentuk kearifan lokal di Sungai Batang Tebo Kabupaten Bungo Provinsi Jambi.

\section{METODOLOGI PENELITIAN}

Penelitian ini dilaksanakan pada bulan November 2017 sampai dengan juli 2018 di Perairan Sungai Batang Tebo bertempat di tiga lokasi yang di jadikan objek penelitian yaitu : Dusun Tanah Tumbuh Kecamatan Tanah Tumbuh, Dusun Tuo Lubuk Mengkuang, dan Dusun Tebo Muara Pandak Kecamatan Limbur Lubuk Mengkuang Kabupaten Bungo.

Metode penelitian yang di gunakan adalah metode purposive sampling (di pilih secara sengaja) yaitu penentuan stasiun penelitian sesuai dengan tujuan penelitian, metode survey dan wawancara langsung kepada masyarakat yang terlibat di dalam proses Sistem Pengelolaan Lubuk Larangan sebagai bentuk kearifan lokal di Perairan Sungai Batang Tebo Kabupaten Bungo. Sumber data yang di peroleh dari penelitian ini adalah:

a. Data primer yaitu data yang di ambil dari Pemangku Adat, Masyrakat Lokal,

\section{HASIL DAN PEMBAHASAN}

\section{A. Sistem Pengelolaan Lubuk Larangan}

\section{Stasiun I Dusun Tanah Tumbuh Kecamatan Tanah Tumbuh}

\section{a. Perencanaan}

Dari pendapat tiga tokoh diatas dapat di simpulkan, bahwa perencanaan
http://ojs.umb-bungo.ac.id/index.php/SEMAHJPSP ISSN : 2580-0736

masyarakat Nelayan, Pengurus Lubuk Larangan .

b. Data sekunder yaitu data yang di ambil dari literatur terkait kantor Desa, Camat, Statistik, kantor Dinas Perikanan.

Yang menjadi responden yaitu terdiri dari tokoh masyarakat (Ketua adat, aprat Desa, pengurus lubuk larangan dan ahli ). Aparat desa yang di tujukan kepada datuk Rio, Ketua adat yang tujukan langsung kepada Ketua adat atau imam masjid. pengurus Lubuk Larangan ( Pokmaswas) di tujukan kepada ketua dari Pokmaswas Lubuk Larangan tersebut. Selanjutnya Ahli tim tujukan kepada Bapak Kepala Dinas Perternakan dan Perikanan Kabupaten Bungo.

Alasan pemilihan dari tokoh tersebut di karenakan adalah orang yang berperan langsung yang mengetahui secara detail tentang Lubuk Larangan yang berada di desa yang telah di tentukan. Ahli atau Pakar menjadi pembanding .

Untuk analisis data penelitian di gunakan Deskriptif Kualitatif, artinya data yang dikumpulkan diolah selanjutnya dibahas guna untuk menggambarkan keadaan yangsebenarnya. Analisa data dilakukan sejak penelitian di lapangan, sewaktu pengumpulan data dan setelah semua data terkumpul maka di bandingkan dengan pendapat ahli atau pakar untuk mengetahui tentang Sistem pengelolaan Lubuk Larangan yang baik.

pembentukan lubuk larangan di Dusun Tanah Tumbuh berawal dari usulan atau Inisiatip dari Masyarakat yang di Musyawarahkan secara bersama oleh Masyakat Dusun Tanah Tumbuh yang bertujuan untuk menentukan lokasi yang tepat membangun lubuk larangan dan kondisi yang memungkinkan membangun lubuk larangan. Hal tersebut sesuai dengan pendapat Terry (2008), Perencanaan adalah pemelihan dan menghubungkan fakta-fakta, membuat serta menggunakan 
SEMAH : Journal Pengelolaan Sumberdaya Perairan VOL. 2 No. 3

Desember 2018

asumsi-asumsi yang berkaitan dengan masa yang akan datang dengan menggambarkan dan merumuskan kegiatan - kegiatan tertentu yang diyakini dan diperlukan untuk mencapai suatu hasil tertentu.

Hal tersebut perkuat oleh pendapat Dinas Peternakan dan Perikanan Kabupaten Muara Bungo, Lubuk larangan itu terbentuk berdasarkan dengan keinginan masyarakat, karena masyarakat yang berperan langsung dalam pengelolaannya.

\section{b. Pengorganisasian}

Berdasarkan hasil penelitian yang di lakukan Dusun Tanah Tumbuh. Dalam pelaksaan pembentukan lubuk larangan ini di bentuk panitia yang akan mengurus dan melaksanakan pembentukan lubuk larangan. Adapun Panitia Pembentuk Lubuk Larangan.

Menurut Dinas Peternakan dan Perikanan Kabupaten Muara Bungo pembentukan lubuk larangan sebaiknya bermusawarah terlebih dahulu, karna terbentukannya lubuk larangan harus bersama dengan kesepakatan bersama seluruh Masyarakat setempat.

Tabel.1. Susunan Panitia

\begin{tabular}{|c|c|c|}
\hline No & Nama & Jabatan \\
\hline 1. & Efendi & Ketua \\
2. & Gusma hendra & Wakil \\
3. & Hendri & Sekretaris \\
4. & zahari & Bendarahara \\
5. & Abdul rahman & Anggota \\
6. & Pirdaus & Anggota \\
\hline
\end{tabular}

Sumber : Kantor Rio DusunTanah Tumbuh 2018.

\section{c. Pembentukan Lubuk Larangan}

\section{Pembacaan Surat Yasin dan Do'a}

Dari pendapat tiga tokoh di atas dapat di simpulkan bahwa, pembacaan yasin dilakukan oleh nenek mamak dan Masyarakat Dusun Tanah Tumbuh mereka melakukan pembacaan surat yasin
http://ojs.umb-bungo.ac.id/index.php/SEMAHJPSP

ISSN : 2580-0736

langsung dipinggir Sungai Batang Tebo yang akan di bangun lubuk larangan tujuan dari pembacaan yasin supaya aman dari gangguan luar, serta mohon kepada Tuhan Yang Maha Kuasa untuk menjaga dari halhal yang buruk.

Pembacaan surat yasin adalah sebagai pengukuhan atau pagar supaya lubuk larangan yang telah di bentuh itu aman, (Dinas Petenakan dan Perikanan Kabupaten Muara Bungo.)

\section{Kata - Kata Adat}

Selanjutnya di lakukan dengan pembacaan sumpah yang di baca oleh Bapak Ketua Adat yang bernama Abdul Rahman, yang mana di sumapah itu berbunyi " Bunyi sumpah adat atau biso kawi"

"Keatas tidak berpucuk Di tengahtengah di girik kumbang Kebawah tidak berurat. yang artinya : kepala botak atau sulah, dan mata terbelak perut buncit atau kembung. kaki lemas dan tidak bisa bergerak".

\section{Penebaran Benih Ikan}

Dari pendapat tiga tokoh diatas dapat di simpulkan bahwa, penebaran benih ikan di lakukan secara bersama oleh Masyarakat Dusun Tanah Tumbuh serta tamu undangan yang hadir dalam acara pelaksaan pembentukan lubuk larangan Dusun Tanah Tumbuh benih ikan yang tebarkan di dapatkan dari Dinas Peternakan Dan Perikanan Kabupaten Muara Bungo.

Menurut Dinas Peternakan dan Perikanan Muara Bungo. Penaburan benih ikan pada lubuk larangan merupakan langkah awal yang berpengaruh terhadap keberhasilan lubuk larangan.

\section{Pemberian Batas}

Dari pendapat tiga tokoh di atas dapat di simpulkan bahwa, pemberian batasan dilakukan oleh masyarakat Dusun Tanah Tumbuh dengan cara melintangkan tali di atas sungai pada bagian hilir atau hulunya sebagai pembatas pada kawasan 
SEMAH : Journal Pengelolaan Sumberdaya Perairan

VOL. 2 No. 3

Desember 2018

lubuk larangan, bertujuan agar masyarakat mengetahui batas yang tidak boleh di ganggu selama waktu yang telah di tentukan hal tersebut sesuai dengan pendapat,

Hal tersebut di perkuat oleh pendapat Dinas Peternakan dan Perikanan Kabupaten Muara Bungo

Boleh ngasih pembatas dengan melintangkan tali di atas sungai, bahkan lebih luas lebih bagus,kalau seluruh Sungai Batang Tebo ini di

bentuk lubuk larangan semua semakin bagus berarti perairan kita sudah terjaga.

\section{Pembukaan Lubuk Larangan}

Dalam pelaksanaan pembukaan lubuk larangan ada beberapa tahap ritual yang harus di lakukan yaitu :

\section{- Pembacaan surat yasin dan doa}

Dari pendapat tiga tokoh diatas dapat disimpulkan bahwa, bahwa Masyarakat Dusun Tanah Tumbuh berencana sebelum pembukaan atau panen terlebih dahulu di awali dengan pembacaan surat yasin dan do'a , karena penutupan di awali dengan pembacaan surat yasin dan do'a jadi pembukaan harus dilakukan juga.

Dari pendapat tiga tokoh di atas dapat di simpulkan bahwa Lubuk larangan Tepian Napal ini memang belum pernah di panen, karna panen akan di laksakan dua tahun sekali , terbentuk nya pada tahun 2016 maka panennya akan di laksanakan pada tahun 2018. hal tersebut di sesuaikan dengan pendapat Lubis (2010). Panen lubuk larangan sebaiknya dilakukan dua tahun sekali supaya ikan yang dihasil sesuai dengan yang di inginkan, dan mendapatkan hasil yang lebih banyak pada waktu panen.

\section{Pembagian Hasil}

Dana hasil Pembukaan Lubuk Larangan sebesar $15 \%$ dari jumlah hasil pendapatan, di alokasikan untuk Honorium dan biaya opersional Tim Pengawas Lubuk Larangan $85 \%$ diserahkan ke Dusun perdus (2016).
http://ojs.umb-bungo.ac.id/index.php/SEMAHJPSP

ISSN : 2580-0736

\section{Pengawasan}

Penegak Hukum Lubuk Larangan.

Aturan dan sanksi yang berlaku pada Lubuk Larangan Tepian Napal Dusun Tanah Tumbuh.

Barang siapa terbukti dengan sah dan benar melakukan penangkapan ikan secara illegal dengan alat dan cara apapun didalam kawasan Lubuk Larangan akan didenda dengan uang Tunai sebesar $\mathrm{Rp}$ 10.000.000.- ( sepuluh Juta Rupiah ) dan hutang adat Duo Puluh Penuh Atau Satu ekor Kambing lengkap dengan seasam segaram.

Kelompok Masyarakat Pengawas Pokmaswas

Dari pendapat tiga tokoh diatas dapat disimpulkan bahwa, sistem pengelolaan Lubuk Larangan Tepian Napal ini di bentuk oleh masyarakat atau Pemerintah Dusun, panitia pengurus pegawasan (pokmaswas) yang artinya kelompok masyarakat pengawas di ikut sertakan dalam pengawasan tersebut Pemerintah Dusun sampai dengan Masyarakat setempat. lubuk larangan Tepian Napal ini mendapatkan bantuan dari Dinas Peternakan dan Perikanan Kabupaten Muara Bungo berupa benih ikan dan papan nama untuk lubuk larangan,untuk pokmaswas mendapatkan uang operasional perbulan dari Pemerintah Provinsi. Hal tersebut di sesuaikan dengan pendapat Aulia, dkk: (2010). Di tempat tertentu sudah ada kelompok pengelola khusus untuk lubuk larangan ini. Salah satu tugasnya adalah melakukan pengawasan lebih aktif di bandingkan anggota masyarakat biasa. Pengawas juga akan menjadi pihak yang sangat berkepentingan untuk menjalankan sanksi jika terjadi pelanggaran, bahkan sampai ke proses pengaduan kepada pihak yang berwajib jika di butuhkan. 
SEMAH : Journal Pengelolaan Sumberdaya Perairan

VOL. 2 No. 3

Desember 2018

Tabel 2. Susunan Pokmaswas

\begin{tabular}{|c|c|c|c|}
\hline No & Nama & Jabatan & Ket. \\
\hline 1. & Gusma & Ketua & \\
2. & hendara, S.H & Wakil ketua & \\
3. & Syahbudin.J & Sekretaris & \\
4. & Azhari & Bendahara & \\
5. & Hendri & Anggota & \\
6. & Pirdaus & Anggota & \\
7. & Zaini kamal & Anggota & \\
8. & M. Saleh .R & Anggota & \\
\hline
\end{tabular}

Sumber : Kantor Rio Dusun Tanah Tumbuh

\section{Dusun Tuo Lubuk Mengkuang Dan Dusun Muara Tebo Pandak Kecamatan Limbur Lubuk Mengkuang.}

Dusun Tuo Lubuk Mengkuang merupakan salah satu Dusun yang terletak di Kecamatan Limbur Lubuk Mengkuang.

Di Dusun Tuo Lubuk Mengkuang dan Dusun Muara Tebo Pandak ini merupakan stasiun IIdan III dalam penelitian tentang sistem pengelolaan lubuk larangan sebagai bentuk kearifan lokal di Sungai Batang Tebo.

Berdasarkan hasil penelitian yang di lakukan tentang sistem pengelolaan Lubuk Larangan di Dusun Tuo Lubuk Mengkuang dan Dusun Muara Tebo Pandak ini banyak terdapat kesamaan, supaya mudah dimengerti di Kecamatan Limbur Lubuk Mengkuang saya paparkan satu desa saja yaitu Dusun Tuo Lubuk Mengkuang adalah sebagai berikut:

\section{a. Perencanaan}

Dari pendapat dua tokoh diatas dapat simpulkan bahwa, perencanaan lubuk larangan berawal dari kesadaran masyarakat melihat ikan-ikan yang da di sungai batang tebo hampir punah kemudian mereka melakukan sosialisasi kepada seluruh masyarakat untuk membentuk lubuk larangan dan di musyawarahkan secara bersama untuk menentukan lokasi yang akan di bangun
http://ojs.umb-bungo.ac.id/index.php/SEMAHJPSP

ISSN : 2580-0736

lubuk larangan,dan kapan waktu untuk membentuknya. Hal tersebut sesuai dengan pendapat Abdulrachman, (2010). Perencanaan adalah upaya menyusun berbagai keputusan yang bersifat pokok yang di pandang paling penting dan yang akan di laksanakan menurut urutan nya guna mencapai tujuan yang telah di tetapkan .

Hal tersebut perkuat oleh Dinas Peternakan dan Perikanan Kabupaten Muara Bungo, Lubuk larangan itu terbentuk berdasarkan dengan keinginan masyarakat, karena masyarakat yang berperan langsung dalam pengelolaannya.

\section{b. Pengorganisasian}

berdasarkan hasil penelitian yang di lakukan Dusun Tuo Lubuk Mengkuang dan Dusun Muara Tebo Pandak. Dalam pelaksaan pembentukan lubuk larangan ini di bentuk panitia yang akan mengurus dan melaksanakan pembentukan lubuk larangan. Adapun Panitia Pembentuk Lubuk Larangan.

Menurut Dinas Peternakan dan Perikanan Kabupaten Muara Bungo pembentukan lubuk larangan sebaiknya bermusawarah terlebih dahulu, karna terbentukannya lubuk larangan harus bersama dengan kesepakatan bersama seluruh Masyarakat setempat.

Tabel 3. SusunanPanitia

\begin{tabular}{|c|c|c|}
\hline No & Nama & Jabatan \\
\hline 1. & Marsuni & Ketua \\
2. & Nawawi & Wakil \\
3. & Puad & Sekretaris \\
4. & M . Saleh & Bendarahara \\
5. & Taupik & Anggota \\
6. & Sarkoni & Anggota \\
\hline
\end{tabular}

Sumber : Kantor Rio Dusun Tuo Lubuk Mengkuang.

\section{d. Pembentukan Lubuk Larangan}

ada beberapa tahap atau ritual yang harus di laksanakan yaitu: 
SEMAH : Journal Pengelolaan Sumberdaya Perairan VOL. 2 No. 3

Desember 2018

1. Pembacaan Surat Yasin dan Doa

Dari pendapat dua tokoh di atas dapat di simpulkan bahwa, pembacaan surat yasin dilakukan di pinggir Sungai oleh beberapa masyarakat setempat yang terutama nenek mamak Dusun Tuo Lubuk Mengkuang setelah selesai pembacaan yasin di lanjutkan dengan do'a yang di pimpin langsung oleh ketua adat bertujuan untuk memohon kepada tuhan agar tujuan mereka tercapai dan di ridho'i Allah.

\section{Kata - Kata Adat}

Di Dusun Tuo Lubuk Mengkuang dan Dusun Muara TeboPandak ini tidak ada kata- kata adat, karena sudah merasa cukup dengan pembacaan yasin dan do'a saja.

\section{Penaburan Benih Ikan}

Di Dusun Tuo Lubuk Mengkuang dan Dusun Muara Tebo Pandak ini tidak ada penebaran benih ikan karena belum ada dapat bantuan benih ikan dari Dinas Peternakan dan Perikanan Muara Bungo.

\section{Pemberian batas}

Dari pendapat dua tokoh di atas dapat di simpulkan bahwa, Pemberian batas pada lubuk larangan Dusun Tuo Lubuk Mengkuang di lakukan dengan cara melintangkan tali yang di atas Sungai pada bagian hilir dan hulunya sebagai pembatas Kawasan Lubuk Larangan supaya masyarakat mengetahui batas yang tidak boleh di ganggu.

\section{Pembukaan Lubuk Larangan}

\section{Pembacaan Surat Yasin Dan Do’a}

Dari pendapat dua tokoh diatas dapat disimpulkan bahwa, lubuk larangan Dusun Tuo Lubuk Mengkuang biasanya sebelum di panen kami melakukan rapat atau muyawarah yang di lakukan oleh prangkat dusun, yang bertujuan untuk menentukan kapan waktu yang pas untuk melakukan panen sesuai dengan kondisi alam yang memungkinkan untuk melakukan pembukaan lubuk larangan. Hari pertama
http://ojs.umb-bungo.ac.id/index.php/SEMAHJPSP ISSN : 2580-0736

Masyarakat Dusun Tuo Lubuk Mengkuang melakukan pembukaan dengan pembacaan surat yasin oleh beberapa tokoh adat atau Masyarakat setempat. karena penutupan dengan pembacaan surat yasin, maka pembukaan atau panen akan di lakukan pembacaan surat yasin kembali. Setelah selesai maka lubuk larangan resmi untuk di buka atau bisa di lakukan penangkapan sesuai dengan ketentun oleh panitia.

Panen Lubuk Larangan Dusun Tuo Lubuk Mengkuang.

Dari pendapat dua tokoh diatas dapat di simpulkan bahwa, penen lubuk Larangan Dusun Tuo Lubuk Mengkuang satu kali setahun, sebelum panen dilakukan masyarakat terlebih dahulu melakukan rapat atau musyawarah untuk menentukan kondisi kapan waktu yang baik untuk melakukan panen biasanya pada saat sungai dangkal. Alat tangkap yang boleh digunakan waktu panen. Penen lubuk larangan Dusun Tuo Lubuk Mengkuang menggunakan sisitem uang inset .

Pembagian Hasil Lubuk Larangan

Dari pendapat dua tokoh di atas dapat di simpulkan bahwa Dana hasil pembukaan Lubuk Larangan dialokasikan untuk pembangunan Dusun, Pembinaan kegiatan masyarakat Dusun, perioritas melalui Musyawarah Dusun. Sesuai dengan kebutuhan Masyarakat Dusun Tuo Lubuk Mengkuang . Selama dua tahun ini Dana dari Lubuk Larangan ini di gunakan untuk pembangunan masjid di Dusun Tuo Lubuk Mengkuang dan Dusun Muara Tebo Pandak. Hal tersebut disesuaikan dengan pendapat Lubis (2010), Pembagian hasil Lubuk Larangan dapat di tentukan berdasarkan hasil musawarah masyarakat setempat , atas Dana Hasil Lubuk Larangan sesuai dengan kebutuhan , seperti pembangunan masjid, madrasah atau kas pemuda.

Menurut Dinas Peternakan dan Perikanan Kabupaten Muara Bungo,di Dusun Tanah Tumbuh sudah bagus sitem pengelolaannya begitu juga dengan sitem 
SEMAH : Journal Pengelolaan Sumberdaya Perairan VOL. 2 No. 3

Desember 2018

pembagian hasilnya $15 \%$ untuk Pokmaswas dan 85\% untuk Desa, karena pokmaswas juga mempunyai peran yang penting dalam pengawasan.

\section{d. Pengawasan}

Penegak Hukum Lubuk Larangan Dusun Tuo Lubuk Mengkuang

Aturan dan sanksi yang berlaku pada Lubuk Larangan Dusun Tuo Lubuk Mengkuang.

Dari pendapat dua tokoh diatas dapat di simpulkan bahwa, penegak hukum Dusun Tuo Lubuk Mengkuang Barang siapa terbukti dengan sah dan benar melakukanpenangkapan ikan secara illegal dengan alat dan cara apapun didalam kawasan Lubuk Larangan akan didenda dengan uang Tunai sebesar Rp 5.000.000 (lima juta rupiah) dan hutang adat Satu ekor Kambing . hal tersebut disesuai dengan pendapat Lubis (2010). hukum adat di tentukan oleh kesepakatan bersama atau pun dari hasil musawarah masyarakat

\section{KESIMPULAN DAN SARAN}

\subsection{Kesimpulan}

Berdasarkan hasil penelitian yang telah dilakukan dapat disimpulkan, bahwa sistem pengelolaan lubuk larangan di :

Dusun Tanah Tumbuh Kecamatan Tanah Tumbuh sudah menggunakan sistem pengelolaan yang sesuai dengan kearifan lokal baik dari sistem perencanaan, pengorganisasian, pelaksanaan, dan pengawasan.

Sistem pengelolaan lubuk larangan Dusun Tuo Lubuk Mengkuang dan Dusun Muara Tebo Pandak Kecamatan Limbur Lubuk Mengkuang belum terkelola secara baik hal ini dibuktikan tidak adanya sistem pengawasan terhadap lubuk larangan.
http://ojs.umb-bungo.ac.id/index.php/SEMAHJPSP

ISSN : 2580-0736

terhadap aturan yang akan di akan di buat untuk kepentingan suatu daerah tertentu.

\section{Pokmaswas}

Dari pendapat dua tokoh diatas dapat di simpulkan bahwa, Sisitem pengawasan lubuk larangan di Dusun Tuo Lubuk Mengkuang ini yaitu di limpahkan kepada seluruh Masyarakat setempat, Prangkat Dusun dan di bantu oleh Karang Taruna yang ada di Dusun tersebut.

Lubuk larangan kami ini tidak mempunyai Pokmaswas karna Masyarakat Dusun Tuo Lubuk Mengkuang ini belum memahami tentang pokmaswas tersebut, kami melakukan pengwasannya masih secara bersama-sama.

Hal tersebut diperkuat oleh Dinas Peternakan dan Perikanan Kabupaten Muara Bungo Bagus seluruh masyarakat terlibat dalam pengawasan lubuk larangan akan tetapi harus di sertai oleh Pokmaswas. Pokmaswas mendapatkan uang dana operasional dari provinsi jadi rugilah mereka yang tidak mau membuatnya.

\subsection{Saran}

1. Di perlukan peningkatan sosialisasi menyeluruh dan berkelanjutan kepada masyarakat mengenai programprogramPemerintah khususnya tentang penetapan Kawasan Konservasi Perikanan, Lubuk reservat dan Lubuk Larangan di wilayah Perairan Batang Tebo.

2. Perlunya dukungan pemerintahan dalam penyedian bibit ikan untuk untuk di tebarkan di setiap Lubuk Larangan yang ada di wilayah Perairan Batang Tebo, agar menegah kepunahan akibat eksploitasi yang berlebihan.

3. Di saran untuk Kecamatan Limbur Lubuk Mengkuang agar melaporkan kepada Dinas Peternakan dan Perikanan Kabupaten Muara Bungo. 
SEMAH : Journal Pengelolaan Sumberdaya Perairan VOL. 2 No. 3

Desember 2018

\section{DAFTAR PUSTAKA}

Aminah, N. A. 2011.penelitian tentang peraturan dan adat lubuk larangan di sungai Indrung, RIAU. Jakarta

Dhiaurrahman, M.2015 Laporan studi pustaka kearipanlokal dalam pengelolaansumber Daya pesisir dan laut.

Effendy,T.2003.Kepercayaan

tentangAturan dan Sanksi yang merupakan Kepercayaan Masyaraka Tradosional adalah merupakan Warisan.Penerbit Perpustaka.Jakarta.

Harfia Surma E $d k k, 2008$, Mengatur diri sendiri melalui pengelolaan lubuk larangan,Belajar dari Bungo, mengelola sumber daya alam di Era Desentralisasi, ISBN 978979-1412-47-6, CIFOR Bogor.

Kantor Dusun , 2017 Laporan Tentang Sistem Pengelolaan Lubuk Larangan di Dusun Tanah Tumbuh.

Kantor Dinas Perternakan Dan Perikanan Muara Bungo Jumlah Konservasi Lubuk Larangan Dan Reservart Di Kabupaten Muara Bungo
http://ojs.umb-bungo.ac.id/index.php/SEMAHJPSP

ISSN : 2580-0736

Lubis,Z.B.2005-2010. Pengetahuan Lokal dalam Sistem Pengelolaan Sumberdaya Alam Berkelanjutan ,Warisan Budaya yang Terancam Hilang. Jurnal Antropologi Sosial Budaya Etnovisi.Jakarta

Parwati,A. 2012. Nilai Pelestarian Lingkungan dalam Kearifan Lokal Lubuk Larangan Ngalau Agung . Ilmu Lingkungan Hidup,UNDIP/aparwati@yahoo.c o.id.

Supriatna , J. 2013.Peran Kearifan Lokal dan Ilmu-ilmu kepribumian dalam Pelesterian Alam . Research Center of Climate Change,Universitas Indonesia.Jakarta.

Terry.Z.2014.Sistem Manajemen Kearipan Local Lubuk Larangan.Ilmu Lingkungan Program Pascasarjana Universitas Riau,Local Wisdom Management of Lubuk Larangan Pangkalan Indarung Village Kuantan Singingi District Province Riau . 